\title{
Migration and Osteogenic Differentiation of Mesenchymal Stem Cells on Titanium with a Micro- Patterned Gelatin Matrix
}

\author{
Mariko Kawai', Noriyuki Nagaoka², Masakazu Inubushi1 ${ }^{1}$, Yoshihiro Ito ${ }^{3}$, Yasuhiro Yoshida ${ }^{4}$, \\ Kiyoshi Ohura ${ }^{1}$ \\ ${ }^{1}$ Osaka Dental University, Department of Pharmacology \\ 8-1 Kuzuhahanazono-cho, Hirakata City, Osaka, Japan 573-1121 \\ kawai-m@cc.osaka-dent.ac.jp; inubushi1122@yahoo.co.jp; ohura@cc.osaka-dent.ac.jp \\ ${ }^{2}$ Graduate School of Medicine, Dentistry and Pharmaceutical Sciences, Okayama University \\ 2-5-1 Shikata-cho, Okayama City, Okayama, Japan 700-8525 \\ nagaoka@okayama-u.ac.jp \\ ${ }^{3}$ Emergent Bioengineering Materials Research Team, RIKEN Center for Emergent Matter Science \\ 2-1 Hirosawa, Wako City, Saitama, Japan 351-0198 \\ y-ito@riken.jp \\ ${ }^{4}$ Department of Biomaterials and Bioengineering, Faculty of Dental Medicine, Hokkaido University \\ Kita 13, Nishi 7, Sapporo City, Hokkaido, Japan 060-8586 \\ yasuhiro@den.hokudai.ac.jp
}

\begin{abstract}
Dental implants significantly improve dental occlusion after tooth loss. However, titanium dental implants do not immediately integrate with the host bone. Furthermore, patients who have insufficient bone at the implant site tend to require pre-treatment surgery, such as autologous bone transplantation, which poses significant burden to the patient. Treatment can also be affected by early invasion of epithelial cells into the gingival epithelium, and this can also hinder the success of implant osseointegration. Therefore, there is a pressing need to develop a dental implant that can reduce the burden on the patient and increase the rate and success of osseointegration. We hypothesized that an efficient strategy for rapid and reliable osseointegration could be achieved by controlling the balance of the cellular populations around the dental implant. Thus, in this study, we micro-patterned a titanium surface with a gelatin matrix and investigated how this surface affected the adherence of mesenchymal stem cells to each of the surfaces. We found that the mesenchymal stem cells first adhered to the titanium and then to the gelatin, enabling cell adhesion to be controlled in a time-dependent manner. The alkaline phosphatase (ALP) activity of the cells on the titanium surface was stronger than that of cells on the gelatin matrix, suggestive of earlier differentiation of the cells into boneforming cells. These results suggest that it may be possible to develop functional dental implants that can control the respective populations of epithelial and mesenchymal stem cells
\end{abstract}

Date Received: 2017-05-31

Date Accepted: 2017-08-31

Date Published: 2017-10-16 at the site of implantation, and thereby promote rapid and reliable osseointegration.

Keywords: Dental implant, Titanium, Micropattern, Cell population, Osseointegration.

(C) Copyright 2017 Authors - This is an Open Access article published under the Creative Commons Attribution License terms (http://creativecommons.org/licenses/by/3.0). Unrestricted use, distribution, and reproduction in any medium are permitted, provided the original work is properly cited.

\section{Introduction}

Dental implant therapy is a highly effective treatment for recovering occlusion after tooth loss $[1,2$, 3]. However, for most patients, osseointegration is not rapid, and there is some delay between implantation of the titanium prosthetic and its osseointegration with the native bone [4, 5]. Furthermore, some patients have insufficient bone for adequate implantation, and require surgical pre-treatment involving procedures such as autologous bone transplantation; these types of procedures are a significant burden to the patient $[6,7$, 8]. Others have shown that the cellular milieu can 
profoundly affect the success of an implant, with the early invasion of epithelial cells into the gingival epithelium, which presumably hinders the attachment of mesenchymal cells that will facilitate bone formation and subsequent osseointegration $[9,10]$.

Therefore, to improve the success rate of dental implant treatments, there is a growing need to design a dental implant that can promote rapid and reliable osseointegration with the existing bone at the implant site. We surmised that an efficient strategy for rapid and reliable osseointegration of the dental implant might be achieved by controlling the cell population on the titanium surface of the dental implant. Thus, in this study, we aimed to control the attachment and proliferation of a population of mesenchymal stem cells on a titanium surface.

\section{Materials and Methods}

\subsection{Micro-patterning of the gelatin matrix on the titanium surface}

The synthesis of the photoreactive gelatin and the process of pattern immobilization of the photoreactive gelatin have been described in detail previously[1]. Briefly, a photomask was positioned on the titanium surface, with the light-shield, film-side facing up (Fig. 1a). Photoreactive gelatin was then dripped onto the slits of the photomask (Fig. 1b). The photomask was covered with a base film (Fig. 1c), and then UV radiation was applied to the upper face of the base film to harden the photoreactive gelatin in contact with the film (Fig. 1d). The photomask was then flipped upside down, and UV radiation was applied through the slits of the photomask (Fig. 1e). The base film was detached from the photomask (Fig. 1f), and any unhardened gelatin was washed off using a cleaning solution [1] (Fig. 1g). UV radiation was then applied with the film in water and the gelatin side facing up. The film was removed from the water and dried (Fig. 1h).

\subsection{Cell culture on titanium plates with micro- patterned gelatin matrix}

Micro-patterned titanium plates were placed within the wells of a 24-well plate. Mouse 10T1/2 cells (RIKEN Cell Bank, Japan) (mesenchymal stem cells) were seeded at a density of $1 \times 105$ cells per well onto the plates, and cultured in Dulbecco's modified essential media containing $0.5 \%$ fetal bovine serum at $37^{\circ} \mathrm{C}$ in an atmosphere of 95\% air and 5\% CO2. Cell counts and size measurements were assessed at 1 and $2 \mathrm{~h}$ after the initiation of culture.

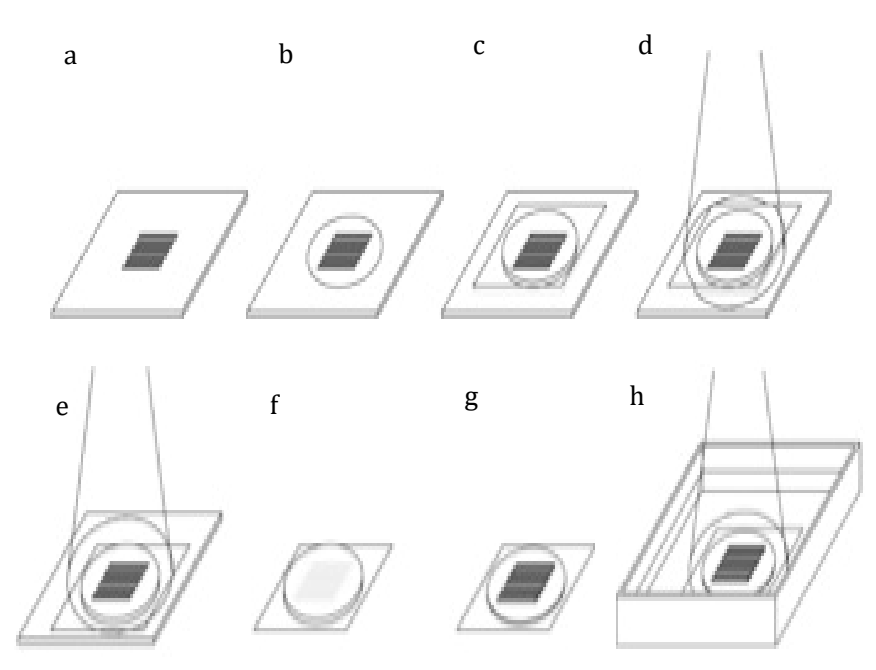

Figure 1. The procedure of immobilization and patterning of the photoreactive gelatine directly to the titanium plate.

\subsection{Observation of cell movement on titanium plates with micro-patterned gelatin matrix}

Cell adhesion and movement on the titanium plates were observed under a phase-contrast microscope in time-lapse sequences. For migration, $1 \times$ $10^{4} 10 \mathrm{~T} 1 / 2$ cells were seeded and grown on titanium plates with micro-patterned gelatin matrix, and microscopic time-lapse observation was performed. To observe cell movement before cell adhesion, time-lapse observations were performed immediately after incubation, and was maintained for $12 \mathrm{~h}$. To observe cell movement after cell adhesion, the cells were incubated for $2 \mathrm{~h}$, and then observed under microscopy for $36 \mathrm{~h}$.

\subsection{Cytoskeletal analysis of cells on titanium plates with micro-patterned gelatin matrix}

To observe how 10T1/2 cell morphology changed on the titanium plate with micro-patterned gelatin matrix, we used fluorescence microscopy to visualize Factin, a constituent of the cytoskeleton, and its binding to phalloidin. 10T1/2 cells were cultured on micropatterned titanium plates, then rinsed in phosphatebuffered saline (PBS) and fixed in a $4 \%$ paraformaldehyde solution for $30 \mathrm{~min}$. Cells were then rinsed in PBS again, and incubated for 30 min in PBS containing $0.1 \%$ Triton X-100. Cells were then incubated for a further $30 \mathrm{~min}$ in $1 \mathrm{U} / \mu \mathrm{L}$ phalloidin at room temperature for fluorescence labelling, rinsed in PBS, embedded in glycerin, and observed under a fluorescence microscope. 


\subsection{Cell culture on titanium plates with cytokine coating}

We fixed $100 \mu \mathrm{L}$ of gelatin matrix and added 1 $\mu \mathrm{g} / \mathrm{mL}$ human bone morphogenetic protein-2 (BMP-2) to the disc-shaped titanium plates. We then distributed 1 $\times 10^{5} 10 \mathrm{~T} 1 / 2$ cells over the entire plate. To measure the degree of bone production, after 10 days of culture, the plates were rinsed in PBS, then fixed in acetone for $1 \mathrm{~min}$. The plates were rinsed again in PBS, and then stained with phenol violet at room temperature in the dark for ALP detection. Plates were again rinsed in sterile water, and observed under a microscope. To quantify the ALP activity of the $10 \mathrm{~T} 1 / 2$ cells, the ALP-positive cells were counted. Statistical analyses were performed using the unpaired $t$ tests.

\section{Results}

3.1. Micro-patterning of the gelatin matrix on the titanium surface, and mesenchymal stem cells

10T1/2 cells, bearing mesenchymal stem cell-like characteristics, were scattered uniformly over the surface of the titanium plates with micro-patterned gelatin matrix at $0 \mathrm{~h}$ (before incubation) (Fig. 2a). At $1 \mathrm{~h}$ after incubation, very few cells were found adhering to

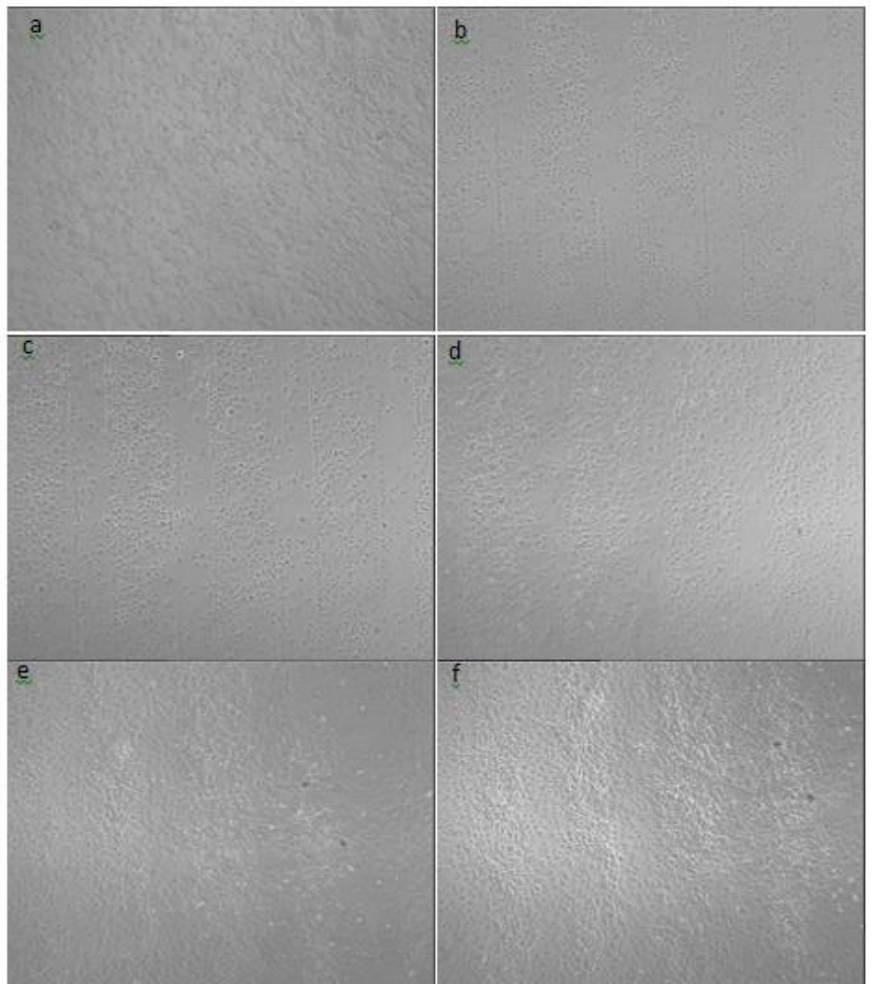

Figure 2. Time course ( $0 \mathrm{~h}$ to $36 \mathrm{~h})$ observation of cell migration of $10 \mathrm{~T} 1 / 2$ cells on titanium with micro-patterned gelatin matrix. the gelatin matrix sections $(100 \mu \mathrm{m})$, whereas numerous cells had adhered to the titanium sections $(200 \mu \mathrm{m})$, forming a pattern (Fig. 2b). At $2 \mathrm{~h}$, cell proliferation was observed, and the pattern of adhesion had been maintained (Fig. 2c). At $5 \mathrm{~h}$, the cells continued to proliferate on the titanium sections, and cells had also started to appear in significant numbers on the gelatin matrix sections (Fig. 2d). At $24 \mathrm{~h}$, numerous cells were observed on both surfaces (Fig. 2e). At $36 \mathrm{~h}$, a bridgeshaped mass of proliferative activity on the titanium sections had expanded to cover the gelatin matrix sections, with further cell proliferation also observed on the gelatin matrix (Fig. 2f).

The number of cells on the titanium was much higher than that on the gelatin (Fig. 3a); however, there was no difference in the sizes of the cells grown on the two surfaces (Fig. 3b).

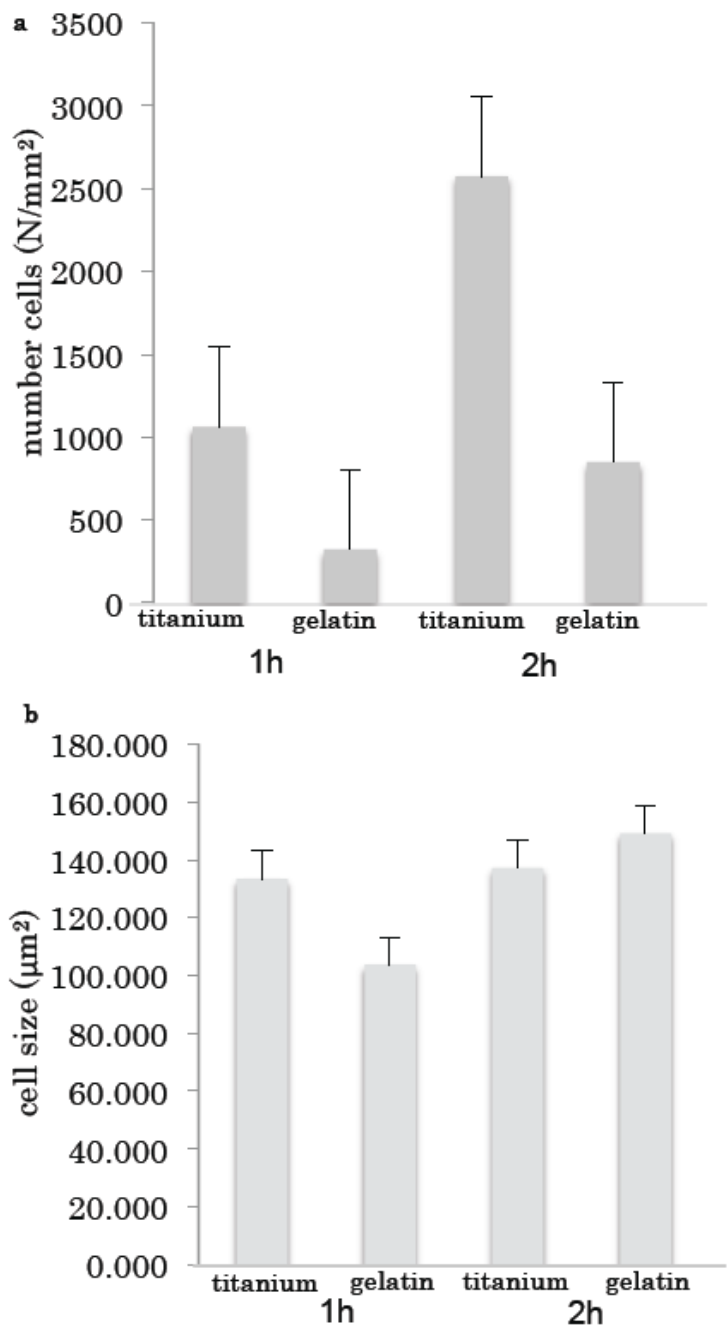

Figure 3. Cell counts and cell size on the titanium and gelatine matrix sections, at 1 and $2 \mathrm{~h}$ after commencement of incubation. 


\subsection{Microscopic observation of early-stage cell movement and morphology on titanium with micro- patterning}

Immediately after commencement of incubation, before the 10T1/2 cells had adhered to the surface, they were almost round (Fig. 4a, arrows). At 20 min after commencement, we observed that some cells had migrated (Fig. 4b, arrows); and at $40 \mathrm{~min}$, some cells continued to migrate (Fig. 4c arrows). At $1 \mathrm{hr}$, cells that had begun to adhere to the surface had changed shape from rounded to rectangular and showed evidence of filopodia formation (Fig. 4d, arrows).
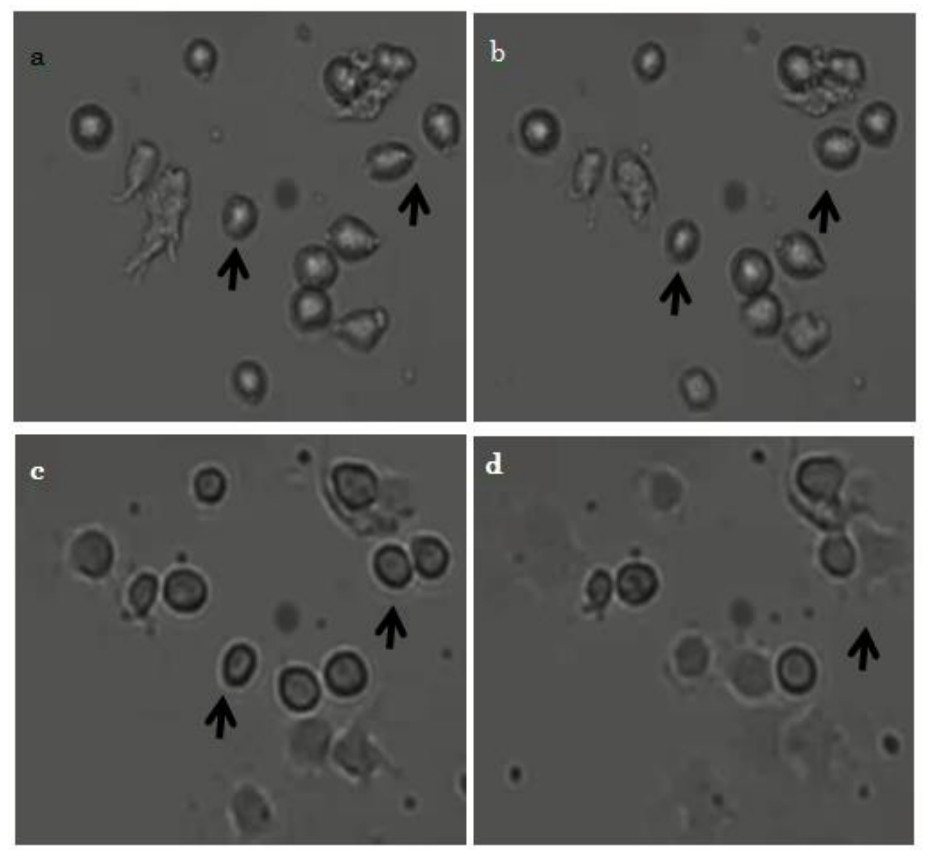

Figure 4. Early-stage cell population on titanium with micropatterned gelatine matrix.

\subsection{Cell movement and morphology on titanium with micro-patterning after cell adhesion}

At $2 \mathrm{~h}$ after the initiation of culture, some cells had already adhered to the plate, and had started to form filopodia and migrate (Fig. 5a, arrowheads). At $2.5 \mathrm{~h}$, the morphology of the cells had further developed; in one example, we show two cells that had begun to form filopodia and were migrating toward each other (Fig. $5 b$ ). After $3 \mathrm{~h}$, these two cells were almost in contact (Fig. $5 \mathrm{c}$ ); and this was achieved by $3.5 \mathrm{~h}$ (Fig. $5 \mathrm{~d}$ ). Cell proliferation was observed from $4 \mathrm{~h}$ (Figs. $5 \mathrm{e}$ and $5 \mathrm{f}$ ). We therefore show that our titanium plates could support cell adhesion, migration, and proliferation. Cells, other than those marked by arrowheads, were also actively forming filopodia and migrating.

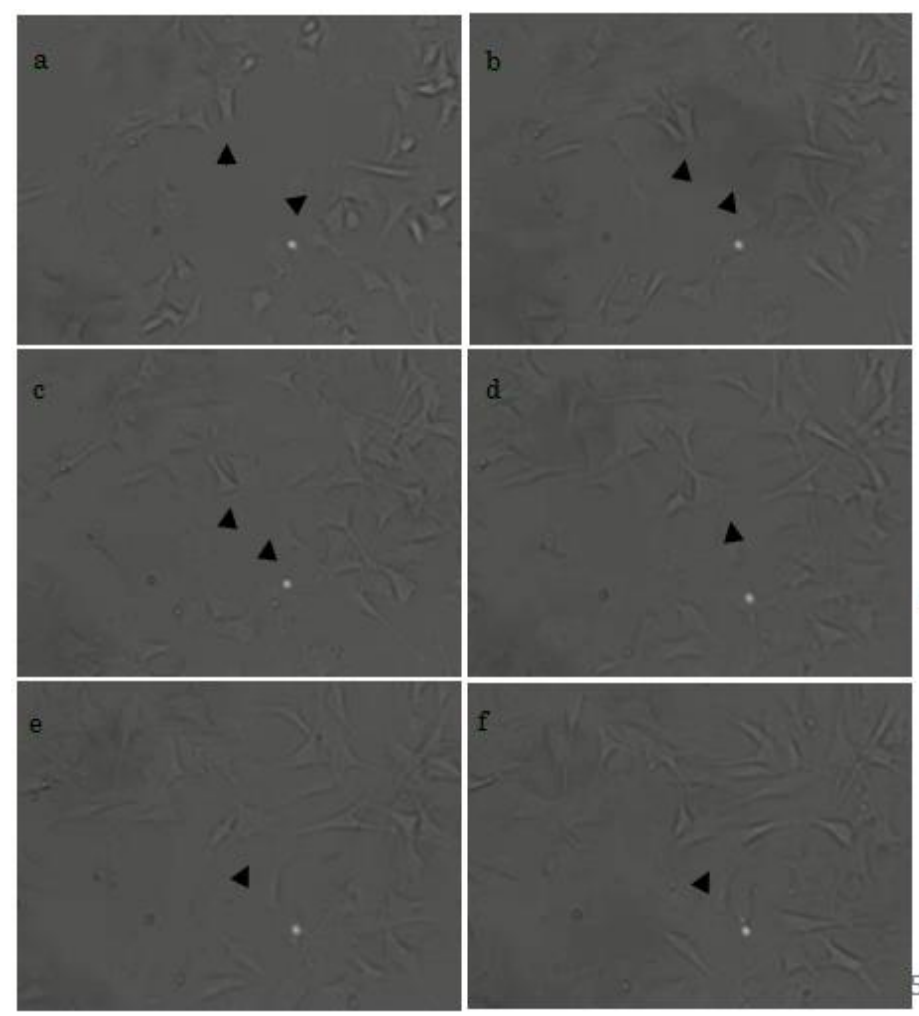

Figure 5. Cell movement and morphology after cell adhesion on titanium micro-patterned with gelatine.

\subsection{Cytoskeleton of $10 \mathrm{~T} 1 / 2$ cells on micro-patterned titanium}

An examination of the cytoskeleton of $10 \mathrm{~T} 1 / 2$ cells on the titanium sections revealed widespread stress fiber formation (Fig. 6, arrow). In contrast, no stress fibers were observed on the gelatin matrix sections; however, a lobopodium-like cytoskeletal structure consisting of F-actin was observed (Fig. 6, arrowhead). The formation of F-actin in 10T1/2 cells differed in cells grown on the titanium sections from those on the gelatin-matrix sections.

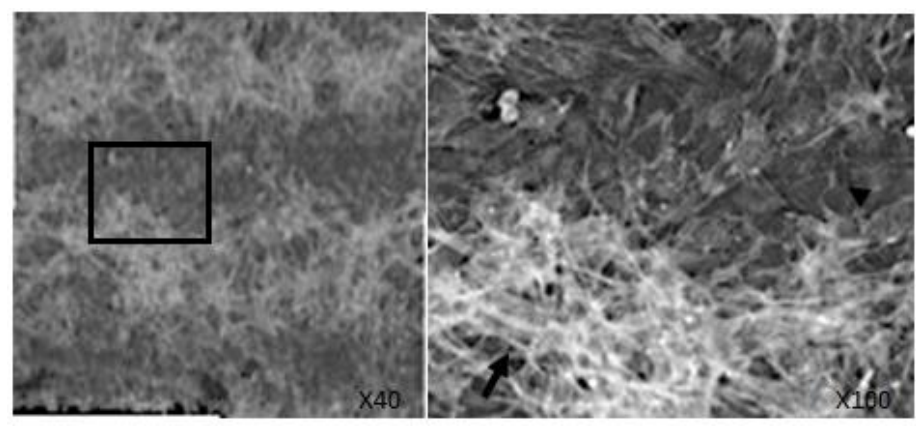

Figure 6. Cytoskeleton of 10T1/2 cells on titanium with micro-patterned gelatine matrix. 


\subsection{ALP activity of $10 \mathrm{~T} 1 / 2$ cells on the titanium with BMP-2}

On the gelatin-matrix sections of the titanium plates (Figs. 7a and 7b, inside the dotted lines), no cells were positive for ALP in the absence of BMP-2 (Fig. 7a); however, numerous ALP-positive cells were observed in the presence of BMP-2 (Fig. 7b arrows). The quantitative data on ALP activity showed that BMP-2 induced greater osteogenic potential in cells grown on the titanium than for those grown on the gelatin (Fig. 7c).
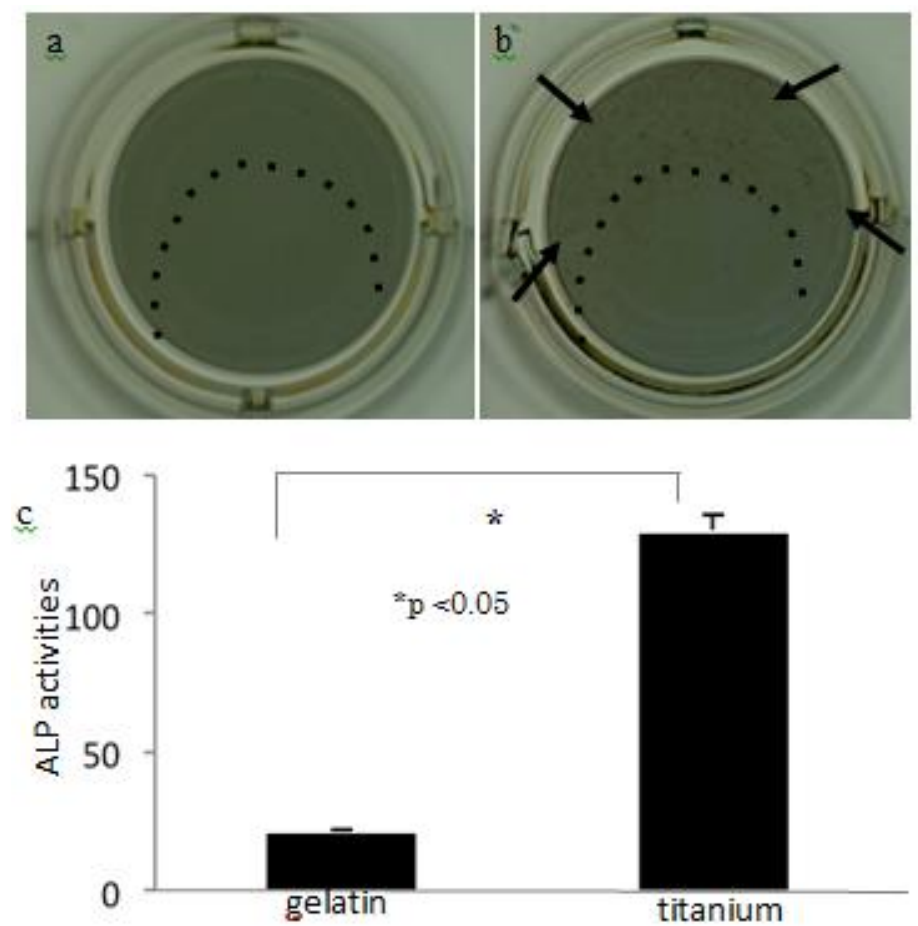

Figure 7. ALP activity of 10T1/2 cells with BMP-2, on titanium and gelatin.

\section{Discussion}

We analyzed the attachment, distribution and osteoinductive potential of mesenchymal stem cells on titanium plates with a micro-patterned gelatin matrix. $10 \mathrm{~T} 1 / 2$ cells, which are an established cell line with the characteristics of mesenchymal stem cells, adhered better to the titanium sections than to the gelatin-matrix sections, resulting in pattern formation based on the fabrication process. This pattern was observed within 1 $\mathrm{h}$ after incubating the cells, and suggested that 10T1/2 cells adhered more easily to the titanium than to the gelatin. However, after $24 \mathrm{~h}$, we found that cells had also started to adhere to the gelatin matrix. This suggests that it may be possible to control the timing of adhesion of mesenchymal stem cells by applying a gelatin matrix to the surface of the titanium. In terms of the osteoinductive potential of mesenchymal stem cells on titanium, these cells showed increased osteogenic activity earlier than those on the gelatin matrix.

In our previous work, we used monkey COS-7 cells as an epithelial cell line and found that these cells adhered better to the gelatin than to the titanium [1]. We suggest that the discrepancies between this study and our previous study may be caused by differences in the characteristics of epithelial-like and mesenchymal-like cells. Mesenchymal stem cells have greater motility, different adhesive factors (such as $\mathrm{N}$-cadherin, vimentin, and fibronectin), and different cell polarity than do epithelial cells $[12,13]$. Furthermore, from a materials science perspective, the gelatin in this study was directly immobilized onto the surface of titanium without ODS treatment, which contrasts with that in our previous study [1]. The gelatin might interfere with cell adhesion, given its diffusive properties as a physicochemical hydrophilic gel layer.

In dental implant treatment, rapid and reliable osseointegration is the key to success [4, 5], and the adhesion of epithelial cells over mesenchymal stem cells prohibits osseointegration $[9,10,14,15]$. Therefore, controlling the respective populations of epithelial and mesenchymal stem cells to shift the balance in favor of mesenchymal stem cells could help to ensure osseointegration. To date, various surface modifications have been developed, such as sandblasting and acid etching (SLA), hydrothermal hot pressing, laser pulse, dip coating, and spray plasma coating $[16,17,18,19,20$, $21,22,23,24,25,26]$. However, as yet, no method has been devised to regulate cell populations in functional dental implants.

In future studies, we plan to analyze the respective populations of oral epithelial cells and mesenchymal stem cells on titanium plates with a micro-patterned gelatin matrix using a co-culture system. The possibility that oral epithelial cells may show greater adherence to the gelatin, and mesenchymal stem cells to the titanium, may create a system for controlling the respective cell populations at the implant site.

\section{Conclusion}

With a focus toward clinical applications, our aim is to develop a dental implant that can be rapidly and reliably integrated with the local host bone. We surmise that suppressing the invasion of epithelial cells while enhancing the population of mesenchymal stem cells at the titanium surface will lead to better osseointegration 
at the bone-implant interface. We suggest that fixing a gelatin matrix at the border between the substructure and superstructure will help to prevent the invasion of epithelial cells from the gingival epithelium and their subsequent adhesion and blocking of the implant titanium surface.

\section{Acknowledgements}

This study was supported in part by the 25 th Grant of the Suzuki Kenzo Memorial Foundation. We thank Rebecca Jackson, PhD, from Edanz Group (www.edanzediting.com/ac) for editing a draft of this manuscript.

\section{References}

[1] M. Heydari, H. Hasuda, M. Sakuragi, Y. Yoshida, K. Suzuki, Y. Ito, "Modification of the titan surface with photoreactive gelatin to regulate cell attachment," $J$ Biomed Mater Res A., vol.83, no.4, pp. 906-914, 2007.

[2] C. E. Misch, Contemporary Implant Dentistry. St. Louis, Missouri: Elsevier, 2007.

[3] B. E. Pjetursson, D. Thoma, R. Jung, M. Zwahlen, A. Zembic, "A systematic review of the survival and complication rates of implant-supported fixed dental prostheses (FDPs) after a mean observation period of at least 5 years," Clinical Oral Implants Research., vol. 23, pp. 22-38, 2012.

[4] D. P. Sinn, E. Bedrossian, A. K. Vest, V. Bedrossian, "Craniofacial Implant Surgery," Oral and Maxillofacial Surgery Clinics of North America., vol. 23, no. 2, pp. 321-335, 2011.

[5] J. Asbjorn, Osseointegration and Dental Implants. New York, NY: John Wiley \& Sons, 2009.

[6] G. A. Zarb, A. Schmitt, "The longitudinal clinical effectiveness of osseointegrated dental implants: the Toronto Study. Part II: The prosthetic results," The Journal of Prosthetic Dentistry., vol. 64, no. 1, pp. 5361, 1990.

[7] M. Peleg, Y. Sawatari, R. N. Marx, J. Santoro, J. Cohen, P. Bejarano, T. Malinin, "Use of corticocancellous allogeneic bone blocks for augmentation of alveolar bone defects," Int J Oral Maxillofac Implants., vol. 25, pp. 153-162, 2010.

[8] J. Caubet, C. Petsold, C. Saez-Torres, M. Morey, J. I. Iriarte, J. Sanchez, J. J. Torres, J. M. Ramis, M. Monjo, "Sinus graft with safescraper: 5-year results," J Oral Maxillofac Surg., vol. 69, no. 2, pp. 482-490, 2011.
[9] L. Castagna, W. D. Polido, L. G. Soares, E. M. Tinoco, "Tomographic evaluation of iliac crest bone grafting and the use of immediate temporary implants to the atrophic maxilla," Int J Oral Macillofac Surg., vol. 42, no. 9, pp.1067-1072, 2013.

[10] M. Brånemark and P. Worthington, Advanced osseointegration surgery: applications in the maxillofacial region. Carol Stream, Illinois: Quintessence Books, 1992.

[11] M. Esposito, M. G. Grusovin, H. Maghaireh, H. V. Worthington, "Interventions for replacing missing teeth: Different times for loading dental implants," The Cochrane Database of Systematic Reviews, vol. 3, 2013.

[12] J. E. Bear, J. M. Haugh, "Directed migration of mesenchymal cells: where signalling and the cytoskeleton meet," Curr Opin Cell Biol., vol. 30. pp. 74-82, 2014.

[13] F. Nitzsche, C. Muller, B. Lukomska, J. Jolkkonen, A. Deten, J. Boltze, " Concise Review: MSC adhesion cascade-insights into homing and transendothelial migration," Stem Cells., vol. 35, no. 6, pp. 1446-1460, 2017.

[14] P. Papaspyridakos, C. J. Chen, M. Singh, H. P. Weber, G. O. Gallucci, "Success Criteria in Implant Dentistry: A Systematic Review," Journal of Dental Research., vol. 91, no. 3, pp. 242-248, 2011.

[15] F. Javed, G. E. Romanos, "The role of primary stability for successful immediate loading of dental implants. A literature review," Journal of Dentistry, vol. 38, no.8, pp. 612-620, 2010.

[16] C. A. Simmons, N. Valiquette, and R. M. Pilliar, "Osseointegration of sintered porous surfaced and plasma spray coated implants: an animal model study of early postimplantation healing response and mechanical stability," Journal of Biomedical Materials Research, vol. 47, no. 2, pp. 127-138, 1999.

[17] C. Knabe, F. Klar, R. Fitzner, R. J. Radlanski, and U. Gross, "In vitro investigation of titanium and hydroxyapatite dental implant surfaces using a rat bone marrow stromal cell culture system," Biomaterials, vol. 23, no. 15, pp. 3235-3245, 2002.

[18] G. L. Darimont, R. Cloots, E. Heinen, L. Seidel, and R. Legrand, "In vivo behaviour of hydroxyapatite coatings on titanium implants: a quantitative study in the rabbit," Biomaterials, vol. 23, no. 12, pp. 25692575, 2002.

[19] Y. Xie, X. Liu, X. Zheng, C. Ding, and P. K. Chu, "Improved stability of plasma sprayed dec alcium silicate/zirconia composite coating," Thin Solid Films, vol. 515, no. 3, pp. 1214-1218, 2006. 
[20] S. Ban, Y. Iwaya, H. Kono, and H. Sato, "Surface modification of titanium by etching in concentrated sulfuric acid," Dental Materials, vol. 22, no. 12, pp. 1115-1120, 2006.

[21] R. Depprich, M. Ommerborn, H. Zipprich et al., "Behavior of osteoblastic cells cultured on titanium and structured zirconia surfaces," Head \& Face Medicine, vol. 4, no. 1, article 29, 2008.

[22] E. Velasco-Ortega, A. Jos, A. M. Camean, J. PatoMourelo, and J. J. Segura-Egea, "In vitro evaluation of cytotoxicity and genotoxicity of a commercial titanium alloy for dental implantology," Mutation Research Genetic Toxicology and Environmental Mutagenesis, vol. 702, no. 1, pp. 17-23, 2010.

[23] C. Aparicio, A. Padros, and F. J. Gil, "In vivo evaluation of micro-rough and bioactive titanium dental implants using histometry and pull-out tests," Journal of the Mechanical Behavior of Biomedical Materials, vol. 4, no. 8, pp. 1672-1682, 2011.

[24] T. G. Eom, G. R. Jeon, C. M. Jeong et al., "Experimental study of bone response to hydroxyapatite coating implants: bone implant contact and removal torque test," Oral Surgery, Oral Medicine, Oral Pathology and Oral Radiology, vol. 114, no. 4, pp. 411-418, 2012.

[25] K. Y. Hung, S. C. Lo, C. S. Shih, Y. C. Yang, H. P. Feng, and Y. C. Lin, "Titanium surface modified by hydroxyapatite coating for dental implants," Surface and Coatings Technology, vol. 231, pp. 337-345, 2013.

[26] A. Jemet, M. J. Ghazali, M. Razali, and Y. Otsuka, "Surface modification and their effects on Titanium dental implants," BioMed Research International., vol. 2015, pp. 1-11, 2015. [Online]. Available: http://dx.doi.org/10.1155/2015/79172 5 